\title{
The realized concept of variable chemical composition fuel gas supply systems, for internal combustion engines
}

The article presents the results of industrial research, of mixer and injection gas supply systems of internal combustion engines, for fuel gas time-varying chemical composition. The publication presents an innovative injection system working by patent PL 222462, and obtained operating characteristics of power generators with the implemented system. In addition for comparison, the article presents the results of research a generator set with implemented an innovative system of the mixing gas fuel supply, with variable chemical composition.

Key words: combustion engine, concepts of supply and control systems, post processing gases

\section{Introduction}

In the era of the rationalization of the use of energy on strives for the smallest loss of energy at every stage of the production processes and exploitation activities. This also applies to the manufacturing processes in which different types of gases are used, including those that are energy carriers. For example, gases of this type of are used on a large scale in industrial processes carried out in the chemical industry, where a large part of them after utilization is post-production waste. In many cases, this creates environmental problems, because the waste gases composition is often very diversified and variable in time. This often does not allow for their further processing or use in standard combustion in heating systems. Only in very few cases their use possible in some systems by mixing the gaseous waste for example with natural gas. Therefore, waste postprocessing gases, are usually subjected to utilization by burning flares, which involves not only the energy losses, but often also with environmental charges for heat and combustion gas emission.

At the Institute of Automobiles and Internal Combustion Engines there were developed innovative concepts for the use of various types of post processing gases with variable chemical composition, as fuel for internal combustion engines, used primarily to drive generators. This is a complex task, especially in the aspect of the need to preserve the constant speed of engine collaborated with a generator. In conventional reciprocating gas engines power system, a sudden change of the chemical composition of the fuel, which is usually accompanied also by changing of the calorific value of the incoming mixture, means a loss of control over the system speed and stability, what enables the procedure to stop the engine operation. These are the reasons due to which the producers of this type of engines do not provide for the possibility of their feeding with fuel, whose chemical composition change significant in a short period of time. The problem is also the use of fuels of low calorific value, compared to conventional fuels, such as for example: natural gas, because the intended parameters of the engine typically requires, the use of engines of large displacement and number of cylinders. It follows that, the greater cost of the investment and less total efficiency of the energy system, due to a greater share of mechanical power loss of engine, relative to its effective power. The other problem determining the possibility of post-processing gases engine feeding, are thermodynamic parameters of fuels and their resistance to detonation. In some industrial processes, particularly chemical, there are fairly large changes in pressure and temperature of the reagents, which also has a significant effect on the thermodynamic state of waste gases.

All of these features of post-processing gases, constitute a substantial barrier to their use as fuel for reciprocating internal combustion engines. Many renowned manufacturers of engines fed with gaseous fuels exclude the possibility of their exploitation for this type of fuels, and requirements usually put at first the condition of chemical composition constant parameters, and thermodynamic state of fuel. For this reason, concepts of waste fuels supply system developed at the Cracow University of Technology, proven in the laboratory and industrial applications, can be innovative considered.

\section{General concepts of engines feeding systems with post processing gases}

Standard gaseous fuel, used to feed the reciprocating internal combustion engines is usually natural gas. Many companies offer this type of industrial and traction engines on the market. Developed in Cracow University of Technology (CUT) concepts of post processing gas engines feeding systems, open up a new area of the use of these fuels for energy purposes. They shall take into account all of characteristics of these fuels, mainly the variability of their parameters in short time intervals and in particular: the chemical composition, the thermodynamic state and resistance to detonation.

The first of the systems was developed for industrial post-processing gases, from the chemical plant, which are available at a pressure greater than 3 bars. For this type of cases, the gas injection supply system was developed. It consisted of an innovative power and igniter control system, which took into account both the nature of the fuel, 
and the volatility of its basic parameters. This system was subjected to laboratory tests in the CUT, and then had been verified in industrial research carried out in a pilot installation, located in one of the "AZOTY S.A." plants. These tests, carried out on the post-processing waste gases that contain a large share of hydrogen, have been launched in March 2014, and in continuous mode are still carried out. Power system was patented under the name: "Method to control regulation parameters in internal combustion engine with spark ignition Patent: PL 222462 B1-WUP 07/16, of 29. 07. 2016.

The second of the developed systems, being in the laboratory phase, is designed to feed the reciprocating internal combustion engines with gaseous fuels, which are available under the pressure close to ambient pressure. This group includes a number of flammable gases from industrial processes or processes of biological decomposition of organic substances. Among them may be mentioned e.g.: biogas, fermentation gas, carbon monoxide, mining gases, metallurgical blast furnace gas or coke oven gas. Developed system can be adapted to feed with one of the fuels or a mixture of gases composed in any proportions.

Total efficiency of engines equipped with developed control systems, to a large extent depends on the calorific value of the fuel and its resistance to detonation. It results among others from the participation of the mechanical losses in the engine, in relation to the achieved work parameters for the specific type of fuel.

Both systems have been adapted to engines that drive generators of electricity, where an extremely important parameters are to maintain constant speed and quick response system to load changing. These parameters are included in the relevant industry standards, and their meeting is a prerequisite for admission of power generators to service. Developed control systems meet the above requirements, also in the event of substantial changes of parameters of the supplied fuel, among others such as: chemical composition, calorific value, or resistance to detonation. In this scope, the created systems provide innovative solutions, which have not been used in products from reputable companies that producing power generators.

\section{The concept of the engines feeding systems witch post-processing gases}

\subsection{General assumptions}

The first realized task connected with the power of internal combustion engines with post-processing gases with changing parameters, was to develop a system that would allow the use of various types of flammable gases, which are waste products from chemical processes carried out in the installation of butanol, isooctanol and aldehydes, located in one of the "AZOTY S.A." plants. According to the factory specifications, the main component in the offered combustible gases, was industrial hydrogen, whose volume share was on average 60 to $90 \%$, then volatile hydrocarbons, carbon monoxide and methane, and the whole was available in the form of mixture with other ingredients. In practice, the chemical composition of the offered gases, subject to rapid and significant change, and volume share of hydrogen often exceeded $90 \%$.
The aim of the research was to develop the engine power and control system, using this type of fuel and adjust it to the requirements arising from the regulations allowing power generators into operation and providing them with the most favourable working conditions. For this reason, it became necessary to identify new issues related to engine cooperation with power generator and also achievement in research as good as possible, working and ecological parameters of engine. The study focused on determining the most favourable energy performance and emission of toxic components, for an engine running at a constant speed of $1500 \mathrm{rpm}$ under changing load. This type of conditions corresponds to the work of the internal combustion engine in the power-plant generator.

Among the control parameters of the tested engine that had to be matched to the type of tested fuel, were belonged primarily: ignition timing and the air excess number.

Both of these parameters have a very significant impact on the process of combustion in the cylinder of the engine, hence both the value of the obtained energy performance and emission of toxic components. In addition, they affect the exhaust gas temperature intensively - directly through the combustion temperature and indirectly, due to the combustion process. It is important to place and time of heat release from the fuel. In the case of research this is crucial due to the raised by engine manufacturer criterion of the maximum value of exhaust gas temperature. In the case of the tested engine exhaust gas temperature may not exceed $700 \mathrm{C}$, due to the thermal strength of the turbocharger (turbine). This is relevant in determining the maximum power of engine fed with the given type of fuel. In addition, both the value of the air excess number, and especially the angle of ignition timing have a close relationship with the occurring phenomenon of the knock. For this reason, for the test fuel and for each engine operation (load) point, both of these regulatory parameters were set individually.

In the conducted analyses, three selection criteria of engine regulation parameters were assumed, for which the engine load was selected, when engine was powered by a particular fuel:

- max. engine exhaust gas temperature may not exceed $700 \mathrm{C}$,

- may not be an anomaly in the form of a knocking combustion,

- may not be the phenomenon of reverse flame to the intake manifold.

During the laboratory tests the value of concentration of: carbon monoxide (CO), hydrocarbons THC, nitric oxide, carbon dioxide $\mathrm{CO}_{2}$ and oxygen $\mathrm{O}_{2}$ have been studied and recorded. In addition, the impact of the test fuel to other engine parameters such as torque and power, fuel consumption, total efficiency, air excess coefficient and exhaust gas temperature have been also studied and recorded.

\subsection{Research facility}

As a laboratory investigation object, a 6-cylinder, supercharged MAN E2876 LE302 engine with a displacement $\mathrm{Vs}=12.82 \mathrm{dm}^{3}$ was selected. The engine, which develops $200 \mathrm{~kW}$ of effective power, has a spark ignition system in its factory configuration and is fed with natural gas by use of air-gas mixer and designed to drive an electric current 
generator. Hydrogen-fuelled engine laboratory tests were carried out at a special test stand at the Internal Combustion Engines Chair Laboratory at Cracow University of Technology.

The choice of this unit was resulted mainly due to the fact that MAN offered a 12-cylinder engine with the same geometric cylinder dimensions. Because the research program's assumptions envisaged the development of a singlecylinder power conversion concept, the modular design of the 6-cylinder and 12-cylinder engine fulfilled the stated condition. All elements of the developed concept of electronically controlled post-processing gas injection system as well as the control system itself were made at the Cracow University of Technology. Equipping of the power generators supplied by HORUS-Energia with all the elaborated and made elements of the system was made also here. After these operations, the aggregates were transported to a specially constructed facility, located in one of the "AZOTY S.A." plants. Fig. 1 shows the aggregates in enclosures during equipping with elements of the system in front of the Engines Laboratory of Cracow University of Technology.

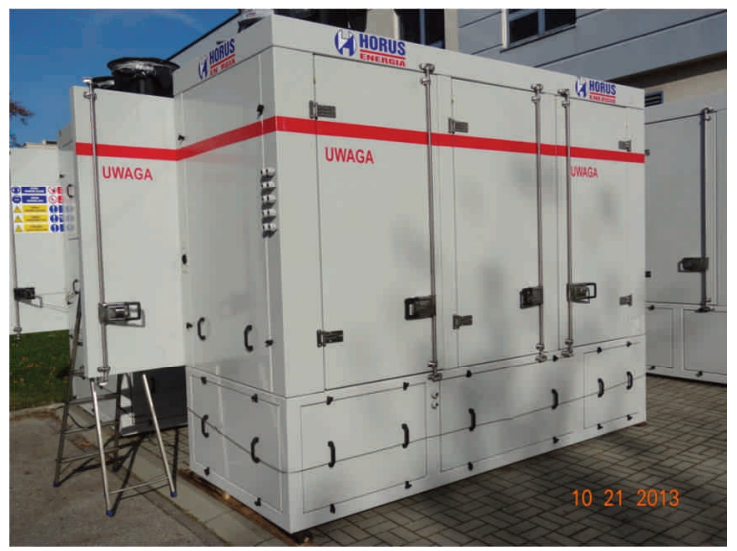

Fig. 1. View of the power-generator set while equipping with elements of the electronically controlled fuel supply system of post-processing gas, in front of the building of Engines Laboratory of Cracow University of Technology

\subsection{Control system}

Practical implementation of the tasks required the design and construction of a special fuel system with a modular configuration similar to Common Rail. The gas fuel feeding system consists of a fuel rail divided into segments corresponding to the number of cylinders. Each segment is equipped with two electromagnetically controlled injectors, which facilitates precise fuel dosage control depending on engine load. There were used standard commercially available natural gas injectors that are used in automotive fuel supply installations. For the purpose of the project, they were modified by increasing the gaseous fuel flow rate and calibration was performed next. Each of the injectors was individually controlled by the control signal, allowing for individual adjustment of the air excess number in each cylinder. The ignition system has been significantly modified, providing the possibility of individually adjusting the ignition angle in each of the engine cylinders. The value of the ignition advance angle was dependent on the signals from the knock sensors, in which each of the cylinders was equipped. The fuel supply and ignition system of the 6cylinder engine are shown in Figure 2 and the 12-cylinder engine in Figure 3.

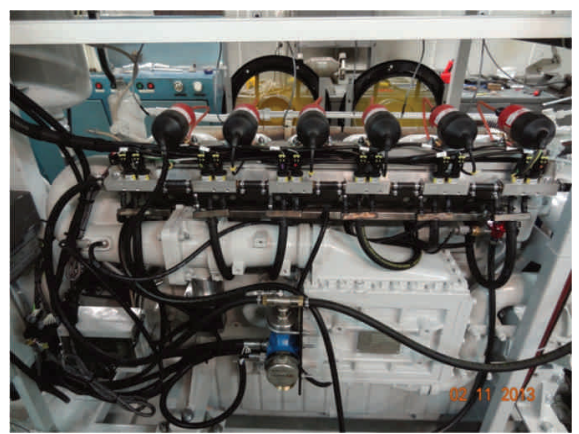

Fig. 2. Ignition system and post-process gas fuel supply system of 6-cylinder engine

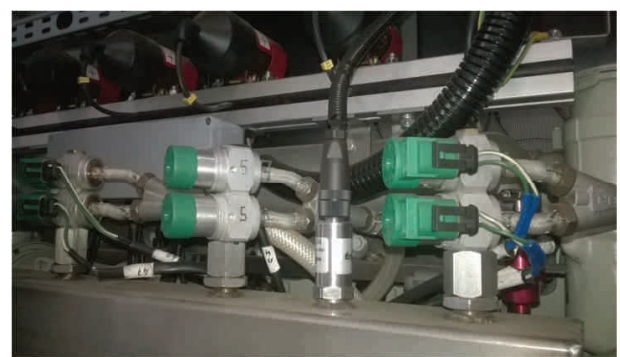

Fig. 3. Post-process gas fuel supply system of 12-cylinder engine

Original spark plugs, recommended by MAN during natural gas supply, were replaced by spark plugs where the spark channel of spark plug was more put out into the combustion chamber. This change has been made on the basis of experimental research and has resulted in a significant improvement of ignition initiation of fuel mixtures. This change was especially important when the engine was powered with a very lean air-gas mixture.

At Cracow University of Technology, a special controller was designed and manufactured to control the most important engine regulation parameters, such as: gaseous fuel dose, ignition angle, throttle opening, and the value of air excess number. This programmable engine controller was developed in LabView. The modular nature of the power and ignition system enabled the combustion process to be monitored in each of the cylinders. This was accomplished by measuring the exhaust gas temperature, individually measured by thermocouples, located in the outlet channel of each cylinder, directly at the exhaust gas outlet from the cylinder head. The individual measured exhaust temperature measured uniquely identifies the amount of heat generated in each cylinder, and is also a diagnostic tool that informs about combustion disturbances, such as chronic combustion effected by too lean an air-gas mixture, or misfire. In addition, the controller, in adaptive mode, continuously cooperated with knock sensors so and thanks to that it uniquely determined the knock limit for each cylinder in all analysed engine operating conditions. This type of supervision and regulation has allowed for high energy conversion efficiency in each of the engine cylinders. A control panel has been built into the control system, the external view of which is shown in Fig.4. 


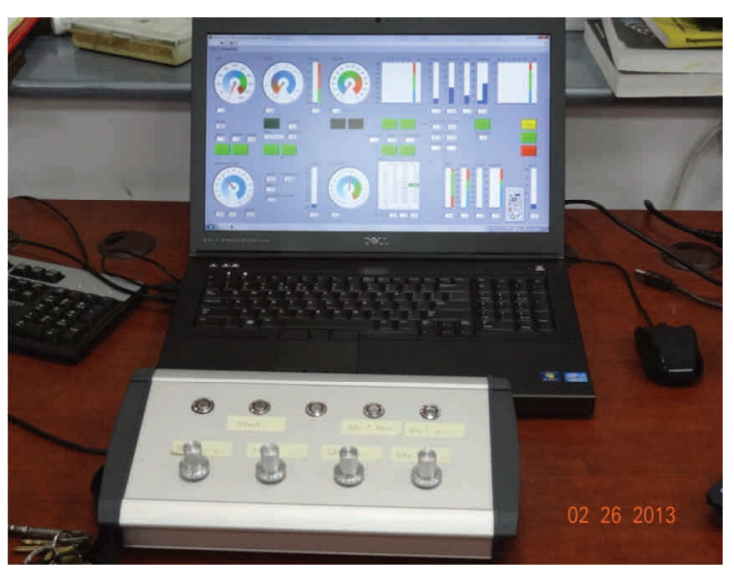

Fig. 4. General view of the control panel of the programmable controller

\subsection{Operating industrial research}

Based on the developed concept of engines injection feeding with post processing gases, at Cracow University of Technology was done the project, components of the system were made and three engines have been equipped with them: one 6-cylinder with a nominal power of $200 \mathrm{~kW}$ and two 12-cylinder engines with a nominal power of $400 \mathrm{~kW}$. The total rated power of three motors prepared for exploitation tests was $1 \mathrm{MW}$, assuming the supply of natural gas, while the power output at the other chemical compositions feeding was respectively lower. The engines, after being equipped with the developed post-processing fuel supply system, were connected to the generators and placed in the HORUS-Energia unit. In such form, the units, marked with the symbols AK-1, AK-2 and AK-3, were put into operation in February 2014 in a facility, located in one of the "AZOTY S.A." plants. Up to now, engines run continuously, depending on the supply of gaseous post-processing fuel, as source of generating electricity and heat. During the operation a number of studies were conducted, the results of which confirmed the preliminary assumptions of the developed concept. Figure 5 shows the aggregates working in a specially built facility, located in one of the "AZOTY S.A." plants.

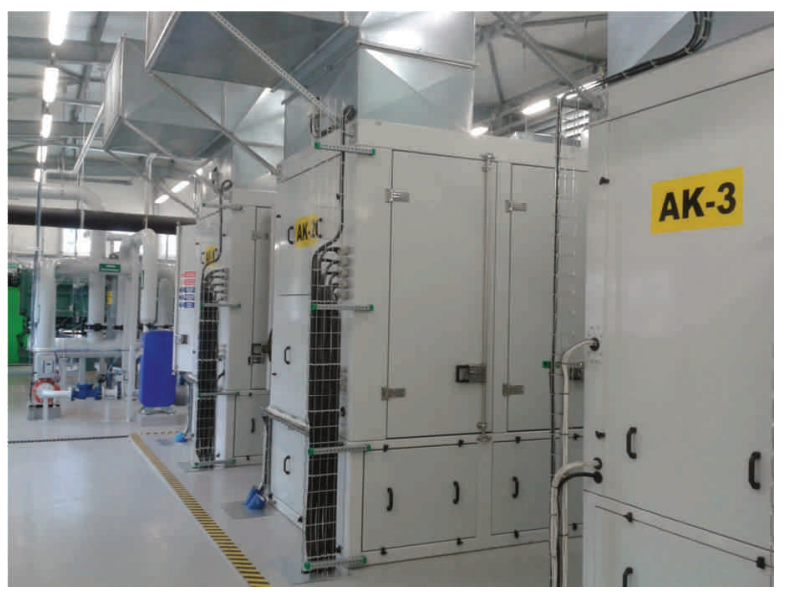

Fig. 6. Power generators with electronically controlled, post-processing gas injection system, located in one of the "AZOTY S.A." plants

Measurements made during the operational tests of the 6-cylinder AK-3 engine showed that in the case of waste gas fuelling, with hydrogen content of about $60 \%$, it is possible to obtain $167 \mathrm{~kW}$ of apparent power. With respect to the internal combustion engine of this aggregate, a predicted cylinder power of about $30 \mathrm{~kW}$ was obtained. The corresponding fuel consumption was about $1 \mathrm{Nm}^{3} / \mathrm{kWh}$. According to exploitation investigations, such level of performance from the cylinder is only obtainable in the case of an AK3 engine. However, under standard operating conditions, this unit was able to operate safely with a load of only $140 \mathrm{~kW}$ due to the limitations of peripheral equipment. For $\mathrm{AK} 1$ and $\mathrm{AK} 2$ engines with 12-cylinder engines under comparable operating conditions as for the AK3, $260 \mathrm{~kW}$ apparent power was obtained. Similarly to the AK3, under standard operating conditions, this unit, due to the limitations of peripheral equipment, was able to safely load up to $230 \mathrm{~kW}$.

During the 8-month exploitation tests, the balance sheet was as follows:

AK1 - 3992 h, energy - 816 MWh, average load - $204 \mathrm{~kW}$

AK2 - 3490 h, energy - $668 \mathrm{MWh}$, average load - $191 \mathrm{~kW}$

AK3 - $3938 \mathrm{~h}$, power $-470 \mathrm{MWh}$, average load - $119 \mathrm{~kW}$

This data covers the entire exploitation period, hence the calculated average load of the individual aggregates is below the nominal value obtained currently during continuous operation.

The most spectacular effect of the use of high-hydrogen waste gaseous fuel was to obtain practically zero emissions of toxic exhaust gas components. Control measurements made during the operation of the 6-cylinder AK3 engine in a variable load field fully confirm the pro-ecological usefulness of such waste fuels. At the operating point of the engine, which corresponded at the given exploitation conditions a maximum value of $167 \mathrm{~kW}$, only $0.3 \% \mathrm{v} / \mathrm{v} \mathrm{CO}_{2}$ and $59 \mathrm{ppm} \mathrm{NO}_{\mathrm{x}}$ were found in the exhaust gas. The result was a combination of both the chemical characteristics of the fuel used and the way in which the mixture composition and engine power were controlled. The nominal 1MW power of three aggregates was determined by natural gas and so a fuel with high knock resistance and a calorific value of about $36 \mathrm{MJ} / \mathrm{Nm}^{3}$. The operating parameters achieved by the engine depend obviously on the characteristics of fuel that power the engine. The fuel with hydrogen volumetric share of about $94 \%$ (by chromatographic analysis) has a calorific value of about $11 \mathrm{MJ} / \mathrm{Nm}^{3}$. The AK3 generator of $200 \mathrm{~kW}$ rated power fed with this fuel has an apparent power of $167 \mathrm{~kW}$ and an active power of $162 \mathrm{~kW}$ with gas consumption of $44.6 \mathrm{~m}^{3} / \mathrm{h}$, which gives 165.5 $\mathrm{Nm}^{3} / \mathrm{h}$. The energy stream in this fuel is $506 \mathrm{~kW}$, so the efficiency of electricity generation is 0.33 .

The obvious effect is also the extremely low carbon dioxide emissions per unit of produced energy. On average, over a period of supervised operation of the aggregates, a value of slightly over $25 \mathrm{~kg} \mathrm{CO}$ per $1 \mathrm{MWh}$ of produced energy was obtained, which is an incomparably less, than the emission achieved in electricity generated by coal-fired power plants, which can be as high as $1000 \mathrm{~kg}$ of $\mathrm{CO}_{2}$ per 1 MWh. This extremely beneficial effect results from feeding the aggregates with fuel of high hydrogen volumetric share and very low carbon share, which is a characteristic feature of used waste post processing fuels. 
The obtained engine working parameters, should be considered to be a great achievement on scientific, technical and economic scale if the properties of the fuel are taken into account. This system as so far has been working well correctly with very high variability of fuel composition and does not cause exploitation problems which positively pays for its further industrial applications.

\subsection{Operational verification investigations during coke oven gas feeding}

An additional element of verification of the innovative concept of the engines gas fuel supply systems, in which engine parameters adapts to the fuel properties was to carry out a coke oven gas feeding test. It is a gaseous fuel with a limited range of application for feeding engines mainly due to its physicochemical properties and constant impurities. In the conducted research at the "AZOTY S.A." plants, the coke oven gas was derived from the factory network and before being supplied to the engine was dried and cleaned in the installation developed by WT \& T company.

Measurements made on an AK-3 engine equipped with a 6-cylinder engine. When powering the engine with coke oven gas with a hydrogen content of $50-60 \%$, it was possible to obtain apparent power up to $202 \mathrm{kVA}$, which corresponded to the designed cylinder power at $35 \mathrm{~kW}$. The corresponding unit consumption of fuel was about 0.6 $\mathrm{Nm}^{3} / \mathrm{kWh}$, corresponding to $33 \%$ efficiency of electricity generation. Performance tests were carried out over a period of 100 hours, while in continuous operation the aggregate was loaded at approximately $50 \%$ of the maximum value obtained in the measurements, which resulted from the constraints of the systems collaborating with the engine. On the basis of the measurements and results of earlier work, it can be predicted that under normal operating conditions, the aggregate can be safely loaded up to approximately $140 \mathrm{~kW}$, due to the limitations of peripheral equipment. The significant effect of coke oven gas application is the very low emission of exhaust gas toxic components (Table 1).

Table 1. Selected values of concentration of exhaust gas components, during coke oven gas engine fuelling

\begin{tabular}{|c|c|c|c|c|c|c|c|c|}
\hline \multicolumn{8}{|c|}{$\begin{array}{l}\text { Volumetric concentration of exhaust gas components } \\
\text { (fuel - coke oven gas) }\end{array}$} & \multirow[b]{2}{*}{$\lambda$} \\
\hline No. & $\begin{array}{l}\mathrm{N}_{\text {effect }} \\
{[\mathrm{kW}]}\end{array}$ & $\begin{array}{l}\mathrm{N}_{\text {electr }} \\
{[\mathrm{kW}]}\end{array}$ & $\begin{array}{l}\mathrm{CO} \\
{[\%]}\end{array}$ & $\begin{array}{l}\mathrm{CO}_{2} \\
{[\%]}\end{array}$ & $\begin{array}{c}\mathrm{HC} \\
{[\mathrm{ppm}]}\end{array}$ & $\begin{array}{c}\mathrm{O}_{2} \\
{[\%]}\end{array}$ & $\begin{array}{l}\mathrm{NO}_{\mathrm{x}} \\
{[\mathrm{ppm}]}\end{array}$ & \\
\hline 1. & 200 & 196 & 0.02 & 4.4 & 6 & 9.2 & 139 & 1.70 \\
\hline 2. & 183 & 181 & 0.02 & 4.4 & 6 & 9.0 & 137 & 1.70 \\
\hline 3. & 162 & 160 & 0.02 & 4.4 & 7 & 9.1 & 130 & 1.70 \\
\hline 4. & 145 & 142 & 0.02 & 4.4 & 7 & 9.1 & 123 & 1.70 \\
\hline 5. & 124 & 122 & 0.02 & 4.4 & 7 & 9.1 & 138 & 1.70 \\
\hline 6. & 103 & 102 & 0.03 & 4.3 & 8 & 9.2 & 134 & 1.70 \\
\hline
\end{tabular}

Control measurements made during operation of the AK3 aggregate in variable field of load, fully confirm the pro-ecological usefulness this type of fuel. At the operating point of the engine, which corresponded to the maximum operating conditions of $200 \mathrm{~kW}$, only $0.02 \% \mathrm{v} / \mathrm{v} \mathrm{CO}, 4.4 \%$ $\mathrm{v} / \mathrm{v} \mathrm{CO}_{2}, 6 \mathrm{ppm} \mathrm{HC}$ and $139 \mathrm{ppm} \mathrm{NO}_{\mathrm{x}}$ were found in the exhaust gas. Almost identical results were recorded during engine operation in a 100-hour exploitation cycle. The result was a combination of the chemical characteristics of the fuel that was used, and the way in which the mixture composition, and engine power were controlled.

Studies have also shown that the use of coke oven gas as a fuel for generation of electricity has very good results in reducing carbon dioxide emissions per unit of produced energy. In this field, $677 \mathrm{~kg} \mathrm{CO}_{2}$ per $1 \mathrm{MWh}$ of generated energy was obtained, while the value of this indicator for coal-fired power plants can be up to $1000 \mathrm{~kg} \mathrm{CO}$ per 1 MWh.

Verification studies have fully confirmed the design and operational features of the developed power and control concept, especially considering the "fuel flexibility" of the generating set, which can equally well be powered by natural gas, coke gas and postprocess gas. The obtained indicators for the tested cogeneration unit should be considered to be a significant achievement.

\section{The concept of the gas fuelling mixer system}

A large number of flammable gases are available in the economy, available at pressure close to ambient pressure. Preparing these gases for use in the above-mentioned injection power system requires compressing them to the required pressure of about 3 bars, which is not cost-effective and rationally justified from the point of view of the efficiency of the whole power system. Therefore in the Cracow University of Technology in cooperation with HORUSEnergia firm, an innovative, electronically controlled mixing system of various types of gaseous fuels, for powering the reciprocating combustion engines was developed. This system is currently undergoing laboratory testing, and the concept itself is being prepared to patent pending.

The study was conducted on the same type of 6-cylinder engine that was subjected to extensive laboratory testing during development of the injection fuelling concept described above. This makes it possible to compare both the concepts of power systems and the control of important engine parameters.

The developed electronically controlled mixer system has similar utility features and has a similar control system as the mentioned injection power system. In addition, it has the ability to simultaneous feed the engine with fuels of different physic-chemical characteristics and derived from different sources. It is very important possibility to attach another fuel with other properties to the feeding system without necessity to stop the engine. The developed concept has been adapted for engines that work with electric generators that maintain the condition of steady rotational speed and a fast response of the system to load change. These parameters are included in the relevant industry standards and their fulfilment is a condition for the admission of generators to operation.

Figure 6 shows the test stand at HORUS-Energia firm where the response of the developed control system to the rapid change of engine load parameters or to the change in the engine mixture parameters was investigated. The evaluated effect was the change of electrical quantities that characterize the operation of the generator. 


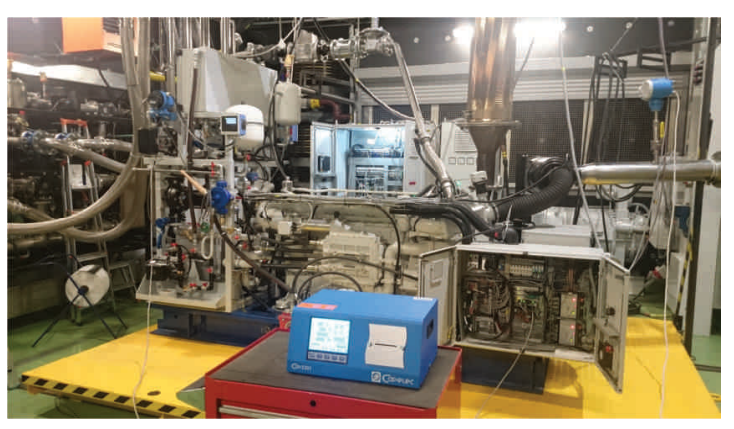

Fig. 6. View of a part of a laboratory test stand with a electric current generator - Horus Energia

In the choice of fuel for combustion engines, the problem is often too low calorific value of fuel because in such cases a high share of engine power losses relative to its effective power results in a reduction of the total efficiency of the power generator unit. Therefore the concept of the system provides for the possibility of co-fuelling and cofiring of fuels with very different calorific values or very different knock resistance. In this range a study of the developed concept has been carried out to investigate the acceptable calorific values of the supplied gas at which the generator engine is able to operate properly.

In laboratory tests, the following gaseous fuels were selected:

- natural gas with carbon dioxide,

- natural gas with propane,

propane with acetylene.

In the first phase of laboratory tests, the minimum calorific value of gas which guarantees stable engine operation was determined. The studies were conducted for natural gas mixtures with carbon dioxide with different proportions of these components, resulting in different fuel calorific values. The ability of the control system to match the engine's control parameters to the changing calorific value was examined.

The next phase of research concerned the so-called high calorific gases, composed for research purposes in different proportions from natural gas and propane. This part of the study was designed to investigate the limitations associated with the thermal load of the engine components, including mainly turbocharger.

The aggregate reaction to gaseous fuels with different knocking tendencies was also investigated. At this stage of the study, a mixture of technical propane and acetylene was used, i.e. an unsaturated hydrocarbon with a very high tendency to knock. In this case, the tests were carried out when the engine was fed with a mixture of these different acetylene gases to determine the reaction of the developed control system to change of the value of octane (methane) number of the fuel, which was used.

The main objective of the described laboratory tests was to determine the limits of the parameters of the fuel used which would be accepted by the developed electronic control system, and also meet all the conditions permitting the fuel to be supplied to the combustion engine.

To determine the dynamic characteristics of aggregate during the load change (which is one of the main evaluation parameters of the fuel supply system quality), only one electric current phase of the generator has been recorded during methane powering. Therefore, to determine the amplitude and frequency, it was necessary to reproduce artificially the voltages of the remaining phases and, in principle, the second voltage vector. This was possible with the assumption of symmetry of phase voltages. An example of the characteristics of the change in the electrical parameters produced in an aggregate equipped with the described power and control system, during a rapid increase in the generator load from 30 to $110 \mathrm{~kW}$, is presented in Fig. 7.

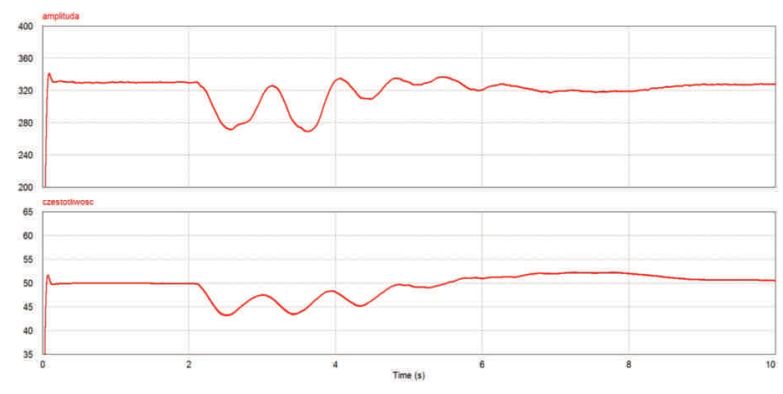

Fig. 7. Changes in generator current parameters with load increase: 30-110 kW

The graph shows that within about 4 seconds after the change of load the basic electrical parameters of the aggregate returned to nominal values. Accordingly, it can be estimated that the developed concept meets the requirements for such generators. Many of these characteristics were made during the change (increase or decrease) of the load, and also during the change of fuel parameters such as calorific value, octane (methane) number or change of thermodynamic parameters. The results of this type of measurement have fully confirmed the usefulness of the developed concept of electronically controlled mixing system of fuelling of reciprocating internal combustion engines with various types of gaseous fuels.

The developed concept can be intended to feed internal combustion engines with all types of gaseous fuels that are available at pressures close to ambient pressure. In practice, this group includes numerous flammable gases from industrial processes or biological decomposition processes. Among them can be mentioned e.g. biogas, fermentation gases, carbon monoxide, mining gas, metallurgical blast furnace gas or coke oven gas. An important feature of the developed concept is the possibility of supplying the engine with one of the mentioned fuels or a mixture of gases, created in any proportions.

\section{Conclusions}

The concepts of innovative power supply and control systems for internal combustion engines, developed in the Cracow University of Technology and in HORUS-Energia firm, designed for use on various types of gaseous fuels, have been made and put into operation. The experience gained during laboratory testing and industrial verification of these concepts allow us to formulate the following key findings:

1. Laboratory tests and industrial verification tests have demonstrated the usefulness of the developed concepts of power supply and control systems for internal com- 
bustion engines designed for operation on various types of gaseous fuels for energetics purposes.

2. The developed concepts are highly flexible in relation to the fuels that are used and at the same time ensure their best energetic utilisation thanks to the system of current analysis and optimization of the most important engine parameters. Modern technical and programmatic tools are used to create a new quality in the discipline related to the design and operation of internal combustion engines.

3. The results of laboratory tests have shown that it is possible to significant extend the types and kind of gaseous fuels that can successfully be used to feed the internal combustion engines.

4. Proper operation of reciprocating engines for different types of gaseous fuels is the result of adopting and applying technical solution much more modern than the feeding and control systems used so far.

5. Much attention was paid to the selection of regulatory parameters including such ones as the ignition advance angle and the air excess number, resulting in favourable operating and ecological indicators of the engine when fuelled with different fuels.

6. The results of the research allowed defining the strategy of fuel supply and control of engine parameters, determining limit values of physic-chemical properties of applied fuels which can be accepted from the point of view of the correct operation of the engine and values of ecological parameters.

7. The obtained scientific and cognitive effects as well as the positive effects of industrial verification tests indicate the existing development potential and the need to seek new concepts of development work in the field of energetics. This type of work meets the postulates of sustainable development which in the energy sector concern mainly rationalizing of energy consumption by reducing losses. In the case of the conducted works the most important result is the energetic utilisation of various types of energy sources in the form of gaseous postprocess fuels which have been so far in large part unproductively lost.

\section{Bibliography}

[1] BRZEŻAŃSKI, M., MARECZEK, M., MAREK, W., PAPUGA, T. Determination of operating parameters of industrial engine fuelled with post processing gases with high hydrogen content. IOP Conference Series, KONMOT 2016, Kraków 2016.

[2] BRZEŻAŃSKI, M., MARECZEK, M., MAREK, W., PAPUGA, T. Określanie parametrów ekologicznych stacjonarnego silnika spalinowego zasilanego różnymi paliwami. Zeszyty Naukowe Instytutu Pojazdów. Warszawa 2014.

[3] BRZEŻAŃSKI, M., CISEK, J., MARECZEK, M. et al. Investigation of the combustion engine fuelled with hydrogen. Combustion Engines. 2013-SC-192.

[4] BRZEŻAŃSKI, M., CISEK, J., MARECZEK, M., et al. Investigations of the fuel supply system of stationary combustion engine fed with natural gas. Combustion Engines. 2013-SC-192.

\footnotetext{
Marek Brzeżański, DSc., DEng. - Faculty of Mechanical Engineering at Cracow University of Technology.

e-mail:MBrzez@pk.edu.pl
}
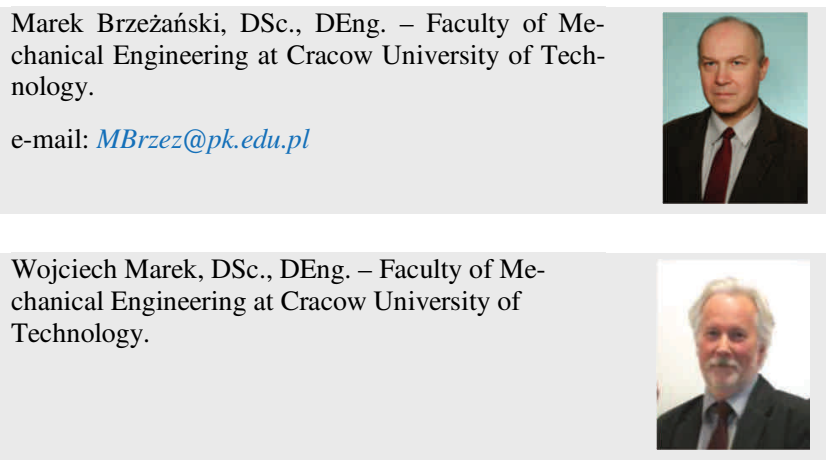

Sutkowski Marek, DEng. - Senior Development Manager in Engine Portfolio Team within Technology \& Solution, Wärtsila Finland Oy.

e-mail: Marek.Sutkowski@wartsila.com

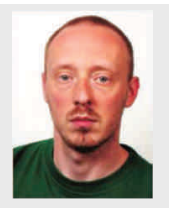

[5] BRZEŻAŃSKI, M., CISEK, J., MARECZEK, M. et al. Investigation of the combustion engine fuelled with hydrogen and mixed n-butanol with iso-butanol. Combustion Engines. 2013-SC-194.

[6] BRZEŻAŃSKI, M., MARECZEK, M., MAREK, W., PAPUGA, T. Zastosowanie odpadowych produktów przemysłu chemicznego w energetyce. III Konferencja Naukowo-Techniczna, Wspótczesne Technologie $i$ Urządzenia Energetyczne. Kraków 2013.

[7] BRZEŻAŃSKI, M., MARECZEK, M., PAPUGA, T. Conception of utilization of the heat from cooling system to increase of the work and ecological parameters of the combustion engine. Combustion Engines. 2011-SC-113.

[8] BRZEŻAŃSKI, M., MARECZEK, M., MAREK, W., PAPUGA, T. Sposób sterowania parametrów regulacyjnych w silniku spalinowym o zapłonie iskrowym. Opis Patentowy nr PL 222462 B1. WUP 07/16.

Michał Mareczek, DEng. - Faculty of Mechanical

Engineering at Cracow University of Technology.

e-mail:Mareczek@pk.edu.pl

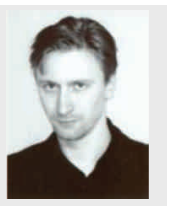

Tadeusz Papuga, DEng. - Faculty of Mechanical

Engineering at Cracow University of Technology.

e-mail: TPapuga@pk.edu.pl

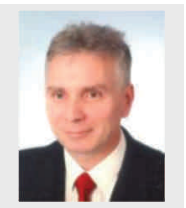

